\title{
CONFLICT OVER MULTIPLE-PARTNER MATING BETWEEN MALES AND FEMALES OF THE POLYGYNANDROUS COMMON LIZARDS
}

\author{
Patrick S. Fitze, $, 1,2,3 *$ Jean-François Le Galliard, ${ }^{1,4 *}$ Pierre Federici, ${ }^{1}$ Murielle Richard, ${ }^{1}$ And \\ JEAN ClOBERT ${ }^{1}$ \\ ${ }^{1}$ Laboratoire Fonctionnement et Evolution des Systèmes Ecologiques, Ecole Normale Supérieure, 46 rue d'Ulm, \\ 75005 Paris, France \\ ${ }^{2}$ Department of Zoology, University of Cambridge, Downing Street, Cambridge CB2 3EJ, United Kingdom \\ ${ }^{4}$ Centre for Ecological and Evolutionary Synthesis, University of Oslo, 0316 Oslo, Norway
}

\begin{abstract}
The optimal number of mate partners for females rarely coincides with that for males, leading to a potential sexual conflict over multiple-partner mating. This suggests that the population sex ratio may affect multiple-partner mating and thus multiple paternity. We investigate the relationship between multiple paternity and the population sex ratio in the polygynandrous common lizard (Lacerta vivipara). In six populations the adult sex ratio was biased toward males, and in another six populations the adult sex ratio was biased toward females, the latter corresponding to the average adult sex ratio encountered in natural populations. In males the frequency and the degree of polygyny were lower in male-biased populations, as expected if competition among males determines polygyny. In females the frequency of polyandry was not different between treatments, and polyandrous females produced larger clutches, suggesting that polyandry might be adaptive. However, in male-biased populations females suffered from reduced reproductive success compared to female-biased populations, and the number of mate partners increased with female body size in polyandrous females. Polyandrous females of male-biased populations showed disproportionately more mating scars, indicating that polyandrous females of male-biased populations had more interactions with males and suggesting that the degree of multiple paternity is controlled by male sexual harassment. Our results thus imply that polyandry may be hierarchically controlled, with females controlling when to mate with multiple partners and male sexual harassment being a proximate determinant of the degree of multiple paternity. The results are also consistent with a sexual conflict in which male behaviors are harmful to females.
\end{abstract}

Key words.-Adult population sex ratio, female choice, Lacerta vivipara, male-male competition, mating system, sexual harassment.

Received April 18, 2005. Accepted August 10, 2005.

Mating with multiple partners is a common phenomenon in many animal species and occurrs in different reproductive systems (Andersson 1994; Shuster and Wade 2003). In polygynous species, it is widely accepted that male fitness depends largely on the number of mating partners (Bateman 1948). However, it is less obvious why females should mate with several males. Females usually produce a limited number of eggs, which can typically be fertilized by a single male ejaculate (Andersson 1994; but see Madsen and Shine 1992). A female might directly or indirectly benefit from multiplepartner mating by obtaining nutrients from the mate, enhancing the genetic quality or diversity of their offspring, or hedging against sterility or genetic defects of her partners (Thornhill and Alcock 1983; Wolff and Macdonald 2004). Mating with several males, however, may be costly for females, for example, due to the enhanced risk of sexually transmitted diseases, the time and energy used for mating, or increased predation risk (Sheldon 1993). Therefore, the optimal number of mating partners may differ between the sexes, resulting in sexual conflicts over multiple-mating decisions (e.g., Parker 1983).

Sexual conflict over multiple mating may drive the antagonistic coevolution of mating tactics in males and females, during which mating behaviors can be selected in one sex despite their negative effects on the reproductive success of

\footnotetext{
${ }^{3}$ Present address: Museo Nacional de Ciencias Naturales, Calle José Gutierrez Abascal 2, 28006 Madrid, Spain; E-mail: patrick.fitze@mncn.csic.es.

*These authors contributed equally to this work.
}

the other sex (Parker 1983; Rice 1996; Martin and Hosken 2003). Although several insect studies attempted to assess the effects of varying sexual conflict on multiple mating (e.g., Thornhill and Alcock 1983; Choe and Crespi 1997; Wigby and Chapman 2004), experimental studies are few in vertebrates (Wolff and Macdonald 2004). However, it has been suggested that in polygynous species where sexual coercion by males seems to be common (Clutton-Brock and Parker 1995), the antagonistic coevolutionary process may lead to the evolution of a mating system in which males control multiple-partner mating rates in females and in which the benefits of male polygamy are potentially harmful to females (for a review see Smuts and Smuts 1993). To our knowledge, in vertebrates this hypothesis has rarely been supported in correlative studies and it has not been tested experimentally (Smuts and Smuts 1993; Byrne and Roberts 1999, 2000; Lee and Hays 2004; Wolff and Macdonald 2004). Such experiments would be complex and costly, requiring an experimental manipulation of the strength of the sexual conflict and estimations of multiple-partner mating and the reproductive costs for females.

We present an experimental field study investigating whether the population sex ratio affects multiple mating in the polygynandrous common lizard (Lacerta vivipara; Laloi et al. 2004). As in previous experiments that manipulated the sexual conflict (e.g., Wigby and Chapman 2004; but see Pizzari and Snook 2003; Arnqvist 2004), we altered the adult population sex ratio in 12 age-structured populations. In six populations the adult sex ratio was biased toward females, corresponding to the average population sex ratio of natural 
populations, while in the other six populations the adult sex ratio was biased toward males. We predicted that females from male-biased (MB) populations would be subjected to more frequent mating attempts and therefore should mate with more males than females from female-biased (FB) populations. We therefore quantified the intensity of male mating attempts by counting the number of mating scars on the belly of the females (Bauwens and Verheyen 1985) and assessed multiple-partner mating by determining paternity of all fertilized eggs using microsatellite genotyping (Laloi et al. 2004). Because males may transfer nonfertile or nonmature sperm and females may select sperm, paternity does not necessarily reflect the number of different males that copulated with a female (Birkhead and Møller 1998). Therefore, we investigated the link between multiple mating and multiple paternity by carrying out a staged mating experiment in the laboratory. Thereafter we tested whether multiple paternity is a facultative response to the population sex ratio, whether the treatment affected the female's reproduction, and which sex potentially controls multiple paternity.

\section{Materials And Methods}

\section{Species Description}

The common lizard is a small ovoviviparous Lacertidae inhabiting nonexclusive home ranges in peat bogs and moist heath lands (Massot et al. 1992). Males emerge from hibernation in February-March, approximately one month earlier than females. After emergence females mate with one to five males (Laloi et al. 2004). During the copulation period males aggressively chase away other males to ensure access to females (Heulin 1988), and adult males are dominant over juvenile males (Lecomte et al. 1994). Mating lasts from a couple of minutes to several hours and is size assortative (Heulin 1988). During mating attempts, a male grips the female on the posterior abdomen with his mouth and then tries to twist his body around the female to introduce its hemipenis into the female's cloacae. As a result of the male's grip, the female's belly shows a U-shaped scar (Bauwens and Verheyen 1985). Mating attempts do not always result in successful copulations, as females may repel the male. Females may repeatedly copulate with the same male (Heulin 1988; P. S. Fitze, pers. obs.). Hence, the number of mating scars does not directly reflect the number of males who successfully transferred sperm but rather the number of male copulation attempts (including repeated copulation attempts by the same male).

In our study populations, a small proportion of the juvenile females (first spring) start reproduction before one year of age and almost all females reproduce after one year of age (Boudjemadi 1999). Pregnancy lasts two to three months, and parturitions occur from the beginning of June until the end of July. Females lay, on average, five transparent, softshelled eggs (range $=1-12$ ). After parturition the offspring hatch within one day and are thereafter autonomous.

In the staged mating experiment described below, $64 \%$ of the females did not copulate with the first presented male, although the males intended to copulate. Under natural field conditions $31-50 \%$ of the females give birth to clutches fathered by a single male (Laloi et al. 2004). These observations suggest that females do not mate at random with all possible males and that they may have different mating or postmating strategies resulting in clutches being fertilized by a single or by multiple males.

\section{Experimental System}

In July 2002, 12 experimental lizard populations $(10 \times 10$ m) were established at the Ecological Research Station of Foljuif (Seine-et-Marne, France, $48^{\circ} 17^{\prime} \mathrm{N}, 2^{\circ} 41^{\prime} \mathrm{E}$ ) using lizards from natural populations of the Mont Lozère area (Cévennes, southern France). The enclosure size corresponds to the female's home-range size. Enclosures were located in a natural meadow and were surrounded by plastic walls to prevent lizards from escaping (for more details see Boudjemadi et al. 1999a). All populations were initiated in July 2002 with 18 adult ( $>$ one year old), 12 yearling (one year old), and 42-45 newborn juvenile common lizards (L. vivipara). The initiated densities and the age structure correspond to the ones observed under natural conditions (Massot et al. 1992). For individual identification, lizards were marked with a unique code using toe clipping.

\section{Experimental Procedures}

In Europe, the adult sex ratio (defined as the proportion of males among adult individuals) varies from $18 \%$ to $65 \%$ males across populations (Heulin et al. 1997). In the Cévennes population from which the lizards used in this study originate (southern France: $44^{\circ} 30^{\prime} \mathrm{N}, 3^{\circ} 45^{\prime} \mathrm{E}, 1420 \mathrm{~m}$ a.s.1.), adult sex ratio variation also occurs on the fine spatial scale of the lizard's home ranges, ranging from $0 \%$ to $80 \%$. The adult sex ratio within the home ranges varies significantly in time and space, is autocorrelated among seasons, and averages $22 \% \pm 21 \%$ SD (22 patches surveyed during 13 years, see Le Galliard et al. 2005).

In this experiment we biased the adult sex ratio of six populations toward males (MB), and in another six populations the adult sex ratio was biased toward females (FB). We released 14 adult males and four adult females in each MB population, and four adult males and 14 adult females in each FB population on July 11, 2002. Thus, the initiated adult sex ratio was $78 \%$ in $\mathrm{MB}$ and $22 \%$ in FB populations. The adult sex ratio of the FB populations corresponds to the average adult sex ratio and thus serves as a control. The adult sex ratio of the $\mathrm{MB}$ populations corresponds to an extreme of the natural variation (see above). The initial snout-vent length (SVL) of the adult females (MB populations: $63.9 \mathrm{~mm} \pm 0.9$ SE; FB populations: $64.4 \mathrm{~mm} \pm 0.4 \mathrm{SE} ; F_{1,10}=0.32, P=$ $0.59)$ and the adult males did not differ between treatments (MB populations: $58.8 \mathrm{~mm} \pm 0.3 \mathrm{SE}$; FB populations: 58.3 $\left.\mathrm{mm} \pm 0.6 \mathrm{SE} ; F_{1,10}=0.82, P=0.39\right)$. Because in the natural population both the yearling and the juvenile sex ratio were equal (1:1) and did not significantly vary in time and space, we manipulated the adult sex ratio only. In all populations six yearling females and six yearling males were released on June 7 and 20-24 juveniles of each sex were released two days after hatching. There were no statistical differences in juvenile sex ratio between $\mathrm{MB}(0.49 \pm 0.01 \mathrm{SE})$ and $\mathrm{FB}$ $(0.49 \pm 0.01 \mathrm{SE})$ populations $\left(F_{1,10}=0.03, P=0.86\right)$, and the initial SVL of yearling males (MB: $49.9 \mathrm{~mm} \pm 0.5 \mathrm{SE}$, 
FB: $\left.49.6 \mathrm{~mm} \pm 0.6 \mathrm{SE} ; F_{1,10}=0.19, P=0.67\right)$ and females (MB: $49.9 \mathrm{~mm} \pm 0.7 \mathrm{SE}, \mathrm{FB}: 49.7 \mathrm{~mm} \pm 0.6 \mathrm{SE} ; F_{1,10}=$ $0.10, P=0.76$ ), and the initial SVL of the juvenile males (MB: $22.6 \mathrm{~mm} \pm 0.1 \mathrm{SE}, \mathrm{FB}: 22.7 \mathrm{~mm} \pm 0.1 \mathrm{SE} ; F_{1,10}=$ $0.30, P=0.59$ ) and females (MB: $23.6 \mathrm{~mm} \pm 0.1 \mathrm{SE}, \mathrm{FB}$ : $23.6 \mathrm{~mm} \pm 0.1 \mathrm{SE} ; F_{1,10}=0.02, P=0.88$ ) did not differ between treatments. In early June 2003 both the sex ratio in lizards older than one year $(\mathrm{MB} 89 \pm 3 \% \mathrm{SE}$; $\mathrm{FB}=33 \pm$ $3 \%$ SE; $\left.F_{1,10}=139.44, P \ll 0.001\right)$ and the sex ratio including all age classes $(\mathrm{MB}=80 \pm 3 \% \mathrm{SE} ; \mathrm{FB}=40 \pm 3 \%$ SE; $\left.F_{1,10}=113.24 ; P \ll 0.001\right)$ were different between treatments. Because sexual maturity and sexual activity are difficult to assess in males that did not father young, it is difficult to exactly determine the operational sex ratio (OSR, defined as the proportion of males that are ready to mate per number of males and females that are ready to mate at a given time). The differences between the OSR including adult males, which are able to reproduce, and the OSR that includes the juvenile males, which may be too young to produce fertile sperm, were small compared to the differences in OSR between the treatments. The data thus suggest that the OSR was between $80 \%$ and $89 \%$ in MB populations and between $33 \%$ and $40 \%$ in FB populations. Consequently, the OSR of $\mathrm{MB}$ populations was around twice as high as in FB populations.

After the mating period (Bauwens and Verheyen 1985), all surviving lizards were recaptured within two consecutive days in late May 2003. All enclosures were regularly checked for live lizards during the two weeks following initial capture to ascertain that all surviving lizards were captured. For each captured lizard, body mass was measured to the nearest 0.01 $\mathrm{g}$ using an electronic balance and SVL was measured to the nearest milimeter. A person unaware of the treatments counted the number of mating scars on each female's belly. All females were individually kept in the laboratory (terraria size: $25 \times 15 \times 15 \mathrm{~cm}$ ) under standardized conditions (heat, light, water, food) until they gave birth. Terraria were heated on one side with a bulb $(25 \mathrm{~W})$ from 0900 to $1200 \mathrm{~h}$ and from 1400 to $1700 \mathrm{~h}$, providing a temperature gradient of $19-24^{\circ} \mathrm{C}$ during the night and $33-35^{\circ} \mathrm{C}$ during the day. Photoperiod was naturally imposed, and a fluorescent UV-light tube was added every four days to mimic outdoor conditions (Iguana Light 5.0 UV-B, 40 W, ZooMed, Sacramento, CA). Animals were fed every fourth day with a moth larva (Pyralis sp.) or with a large cricket (Acheta domestica; for additional details see Le Galliard et al. 2003).

\section{Paternity Assignment}

Before release, in 2002 we collected a small part of the tip $(1 \mathrm{~mm})$ of the regrowing tail of each lizard used in this study. In 2003, we collected a genetic sample from each offspring, dead embryo, and egg laid. All samples were stored in $70 \%$ ethanol. DNA was extracted using Perfect gDNA Blood Mini Isolation kit (Eppendorf, Hamburg, Germany). We used five highly polymorphic microsatellite DNA loci (Lv-3-19, Lv-4-72, Lv-4- $\alpha$, Lv-4-X, and Lv-4-115; Boudjemadi et al. 1999b) to identify the putative fathers. The exact method used for the extraction, the polymerase chain reac- tion, and the determination of the allelic size is described elsewhere (Laloi et al. 2004).

Females gave birth to a total of 753 eggs and offspring. DNA of all offspring and of all except 12 eggs could be extracted. Paternity assignments were done using Cervus 2.0 (Marshall et al. 1998). Because the genetic profile of the mothers and of all potential fathers were known, the program was simply used to facilitate the attribution of the genetic fathers. Analyses were done for each population separately. For all except 12 juveniles, the program found a single candidate father. For the 12 juveniles for whom two fathers fit the juvenile's allelic profile, we analyzed a sixth locus ( Lv2-145; Boudjemadi et al. 1999b), which allowed the determination of a unique candidate father. Three females laid unfertilized clutches (two females [11 eggs] from MB populations and one female [four eggs] from an FB population), and among the females giving birth to fertilized eggs one female from an FB population laid one unfertilized egg. Therefore, all analyses are based on the 725 eggs and offspring that could be successfully attributed to a single father.

\section{Analysis of Multiple Paternity}

For both females $(n=126)$ and males $(n=80)$ that had access to reproduction, we determined whether the female's clutch was fertilized by a single male (hereafter referred to as "single paternity" or "monogamy") or by several males ("multiple paternity", or "polyandry"). In males "single siring" refers to males that sired the eggs of a single female (monogamy) and "multiple siring"' to males that sired eggs of multiple females (polygyny). Second, we determined the number of different partners with which females and males share paternity (degree of polyandry or degree of polygyny).

For the statistical analyses, we used hierarchical models with sex-ratio treatment as fixed effect. Population was nested within treatment and modeled as a random effect. First, the probability of being polyandrous (for females) and the probability of being polygynous (for males) were modeled using Proc GLIMMIX in SAS (SAS Institute, Inc., Cary, NC) using a binomial error distribution and a logit link (Littell et al. 1996). The degree of polyandry and the degree of polygyny were then modeled using Proc GLIMMIX with a Poissondistributed error and a log link. Because clutch size will limit the incidence of multiple paternity and thus may confound variation in multiple paternity between females, we included clutch size as a covariate in our analyses. For males, we conducted two types of analysis: (1) we introduced the total number of eggs fertilized by that male as a covariate; and (2) we accounted for the total number of potentially fertilizable eggs per population. In all statistical analyses, we first fit a full model. If covariates were included in the analysis, the full model contained all possible interactions. We then selected a final model using backward elimination of the nonsignificant terms $(P>0.05)$. Model assumptions were fulfilled in all analyses.

\section{Multiple-Partner Mating and Paternity Assignments}

Estimating the number of mate partners by examining the paternity, rather than by directly observing mating behavior, may be problematic. Information might be lost if some cop- 
TABLE 1. Probability of multiple paternity in females and males in relation to the adult sex ratio (treatment), snout-vent length (SVL), and the number of fertilized eggs. Results stem from a logistic regression using backward selection.

\begin{tabular}{|c|c|c|c|c|c|c|}
\hline \multirow[b]{2}{*}{ Variables } & \multicolumn{3}{|c|}{ Females } & \multicolumn{3}{|c|}{ Males } \\
\hline & $\mathrm{df}$ & $F$ & $P$ & $\mathrm{df}$ & $F$ & $P$ \\
\hline Treatment & 1,10 & 2.68 & 0.133 & 1,10 & 7.46 & 0.020 \\
\hline Number fertilized eggs & 1,113 & 10.33 & 0.002 & 1,63 & 29.07 & $<0.001$ \\
\hline Treatment $\times$ SVL & 1,111 & 1.05 & 0.308 & 1,62 & 1.47 & 0.231 \\
\hline Treatment $\times$ fertilized eggs & 1,109 & $<0.01$ & 0.983 & 1,63 & 11.76 & 0.001 \\
\hline
\end{tabular}

ulations do not result in fertilized eggs, for example, due to infertile sperm, unequal sperm competition, or cryptic female choice (for example, Andersson 1994). Therefore, we conducted an additional laboratory experiment prior to this study in which we sequentially mated 73 females with up to three different males and determined the number of males that fertilized eggs under controlled conditions. For this purpose females and males were introduced in autumn into outdoor enclosures similar to the ones used in our adult-sex-ratio manipulation. Enclosures contained either females only or males only to prevent lizards from mating prior to our laboratory experiments. Within the same study site, other populations containing both females and males were regularly inspected in early spring. The females of these populations were inspected for mating scars to determine when mating happens under natural circumstances (Bauwens and Verheyen 1985). Two days after the first mating scars were detected on the females of these populations, male and female lizards used for this experiment were captured. Subsequently they were introduced into individual terraria and maintained under similar laboratory conditions as described above. The staged mating experiments started the day following capture. Females were introduced into escape-proof wooden boxes (250 $\mathrm{cm}^{2}$ ), containing a shelter and equipped with a $40-\mathrm{W}$ bulb that provided light and heat. An additional UV-B neon light source provided UV-light. Two to four minutes after release each female was provided with a randomly selected male. Thereafter, lizards were observed and the number of copulations was registered. We presented different males to a female until she copulated with two or three males. If a female did not copulate with more than 15 subsequent males, we no longer presented males to her. After the mating experiments, males were released into the enclosure where they originated from, and females were released into two new empty enclosures. All surviving female lizards were recaptured at the end of May, at the same time as the individuals of the main experiment, and the number of mating scars was counted on 39 females. Following capture, females were housed in individual terraria under the same conditions as described above until they gave birth. On the same day a female gave birth, we carefully searched her terrarium for eggs and juveniles, and a genetic sample of all eggs and juveniles was taken. Paternity was analyzed using the same method as described above.

\section{RESULTS}

\section{Multiple-Partner Mating and Multiple Paternity}

Sixty-four percent of the females did not copulate with the first presented male, although the mating experiments were conducted within the mating season. To several females $(5 \%)$ more than 10 different males had to be presented before they copulated for the first time. In $57.1 \%$ of the clutches the eggs were fertilized by males that copulated with the female on the first day she was presented to males, and in $81.0 \%$ of the females eggs were fertilized by male sperm obtained during the first two days. These data show that early copulations lead to the fertilization of the eggs and thus suggest that females are receptive directly after emergence. The number of sires was positively correlated with the number of males a female copulated with $\left(F_{1,71}=18.57, P \ll 0.001, r=0.46\right)$ and with the number of mating scars found on the female's belly $\left(F_{1,37}=11.79, P=0.002, r=0.49\right)$. The number of mate partners was more strongly correlated with the number of mating scars on the female's belly $\left(F_{1,37}=17.66, P<\right.$ $0.001, r=0.57)$ than the number of sires. In males, the number of female partners was also positively correlated with the number of females for which he fertilized eggs $\left(F_{1,134}=\right.$ 89.06, $P \ll 0.001, r=0.64)$.

\section{Multiple Partner Mating by Females}

In MB populations clutches were fertilized by one to four different males (mean: $1.96 \pm 0.19 \mathrm{SE}$ ), and in FB populations they were fertilized by one to five different males (mean: $2.05 \pm 0.09 \mathrm{SE}$ ). In FB populations 72 of 104 females $(69.23 \%)$ and in MB populations 16 of 22 females $(72.73 \%)$ gave birth to eggs and offspring sired by several males. The proportion of polyandrous females was similar in $\mathrm{MB}$ and FB populations (logistic regression: $F_{1,10}=0.11, P=0.75$ ) even after accounting for SVL and clutch size (Table 1).

In polyandrous females a significant interaction between treatment and SVL was present (Table 2, Fig. 1). The number of mate partners increased significantly with female SVL in MB populations $\left(F_{1,11}=4.82, P=0.05\right)$, while it remained almost constant in FB populations $\left(F_{1,66}=0.04, P=0.85\right)$. When removing SVL from the model the treatment effect was no longer significant $\left(F_{1,10}=0.60, P=0.46\right)$, showing that the treatment effect was size dependent. Because clutch size was highly correlated with SVL $\left(F_{1,86}=115.12, P \ll\right.$ $0.001,57.2 \%$ of variance explained) models including SVL or clutch size showed a significant interaction with the treatment (SVL x treatment: $F_{1,77}=5.25, P=0.03$; clutch size $\times$ treatment: $\left.F_{1,77}=7.21, P=0.01\right)$. Because of the collinearity of the two covariates, however, it is difficult to distinguish whether SVL or clutch size is more important and thus whether the interaction between clutch size and treatment or the one between SVL and treatment is more important, although the interaction between treatment and clutch 
TABLE 2. Number of partners in multiple-mated females and males in relation to the adult population sex ratio (treatment), the snoutvent length (SVL), and the number of fertilized eggs. Results stem from a logistic regression using backward selection.

\begin{tabular}{|c|c|c|c|c|c|c|}
\hline \multirow[b]{2}{*}{ Variables } & \multicolumn{3}{|c|}{ Females } & \multicolumn{3}{|c|}{ Males } \\
\hline & $\mathrm{df}$ & $F$ & $P$ & df & $F$ & $P$ \\
\hline Treatment & 1,10 & 6.87 & 0.026 & 1,8 & 11.24 & 0.010 \\
\hline Number fertilized eggs & 1,76 & 12.85 & $<0.001$ & 1,35 & 9.82 & 0.004 \\
\hline Treatment $\times$ SVL & 1,76 & 7.42 & 0.008 & 1,33 & 1.14 & 0.294 \\
\hline Treatment $\times$ fertilized eggs & 1,74 & 0.56 & 0.456 & 1,32 & 0.08 & 0.777 \\
\hline
\end{tabular}

size dropped out first from the model presented in Table 2. Consequently, we cannot show statistically that body size (SVL) is the ultimate factor (Quinn and Keough 2002).

\section{Multiple-Partner Mating by Males}

Males successfully mated with one to three different females in MB populations (mean: $1.27 \pm 0.39 \mathrm{SE}$ ), and with one to 14 different females in FB populations (mean: 3.66 $\pm 0.30 \mathrm{SE})$. Fourty of the 58 successfully mating males $(68.97 \%)$ of FB populations and eight of the 34 successfully mating males $(23.53 \%)$ of MB populations mated with several females. The proportion of polygynous males was significantly higher in FB in MB populations (logistic regression: $\left.F_{1,10}=11.26, P<0.01\right)$. When controlling for $\mathrm{SVL}$, the proportion of polygynous males was still higher in FB than in MB populations (logistic regression: treatment: $F_{1,10}$ $=19.56, P<0.01$, SVL: $\left.F_{1,67}=6.68, P=0.01\right)$, and there was no significant interaction between the treatment and SVL $\left(F_{1,66}=1.32, P=0.26\right)$. The proportion of polygynous males per number of fertilized eggs was also higher in FB than in MB populations (Table 1). However, it no longer differed between treatments when taking the number of potentially

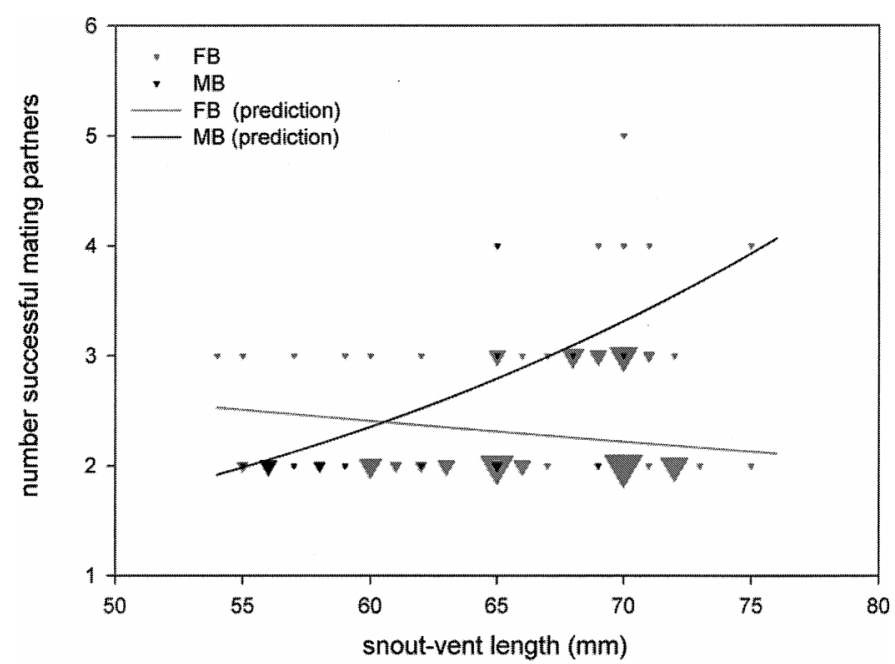

FIG. 1. Number of successful mating partners of polyandrous female common lizards in male- biased (MB) and female-biased populations (FB) in relation to the snout-vent length. The regression lines are derived from a Poisson regression and the back-transformed estimates are shown. Symbols of different size reflect the number of females per point, with the smallest symbol representing one female and the biggest representing seven females. For statistics see Table 2. fertilizable eggs per population into account (logistic regression: treatment: $F_{1,9}=0.04, P=0.84$, number potentially fertilizable eggs: $F_{1,67}=16.58, P<0.001$; SVL: $F_{1,67}$ $=5.29, P=0.03)$. These findings suggest that the level of polygyny increases proportionally to the number of fertilizable eggs present.

The degree of polygyny (the number of different mating partners per male of males that had more than one mate) was higher in $\mathrm{FB}$ than in $\mathrm{MB}$ populations $\left(F_{1,10}=12.36, P=\right.$ $0.01)$, and it increased with $\operatorname{SVL}\left(F_{1,36}=9.73, P<0.01\right)$. However, the interaction between treatment and SVL was not significant $\left(F_{1,35}=0.38, P=0.54\right)$. The degree of polygyny per number of fertilized eggs was also higher in FB than in MB populations (Table 2), but it did not differ between treatments when taking the number of potentially fertilizable eggs per population into account (logistic regression: treatment: $F_{1,10}=2.4, P=0.15$, number of potentially fertilizable eggs per population: $F_{1,36}=10.46, P<0.01$; SVL: $F_{1,36}=8.81$, $P=0.01)$.

\section{Clutch Size in Relation to Treatment and Multiple Paternity}

In MB populations females produced, on average, 3.46 eggs $\pm 0.3 \mathrm{SE}$ per clutch and in FB populations 6.24 eggs $\pm 0.2 \mathrm{SE}$. Females of FB populations thus produced 1.8 times more eggs than those of $\mathrm{MB}$ populations $\left(F_{1,10}=23.30, P\right.$ $=0.001,12.2 \%$ of the variance explained). Multiply sired clutches were larger than singly sired clutches (multiply sired clutches: 5.2 eggs $\pm 0.3 \mathrm{SE}$; singly sired clutches: 4.0 eggs $\pm 0.4 \mathrm{SE} ; F_{1,113}=12.66, P=0.001,6.6 \%$ of the variance explained). There were no significant differences in clutch sizes between populations $\left(F_{10,113}=1.54, P=0.13\right)$, and the interaction between treatment and multiple paternity was not significant $\left(F_{10,112}=0.02, P=0.90\right)$. Including female SVL in the model revealed that there were still significant differences between treatments $\left(F_{1,10}=14.60, P<0.01\right.$, $4.4 \%$ of the variance explained) and between singly and multiply sired clutches $\left(F_{1,112}=4.07, P=0.046,1.22 \%\right.$ of the variance explained), but it reduced the variance explained by the two factors. SVL was significant $\left(F_{1,112}=97.61, P \ll\right.$ $0.001,29.4 \%$ of the variance explained).

\section{Mating Scars}

In our field experiment, 40 of 126 females (31.8\%) showed fewer mating scars than the minimal number of mating scars predicted by the number of sires. This finding suggests that two males were biting the female at the exactly same body position, that some bites did not produce mating scars, or 


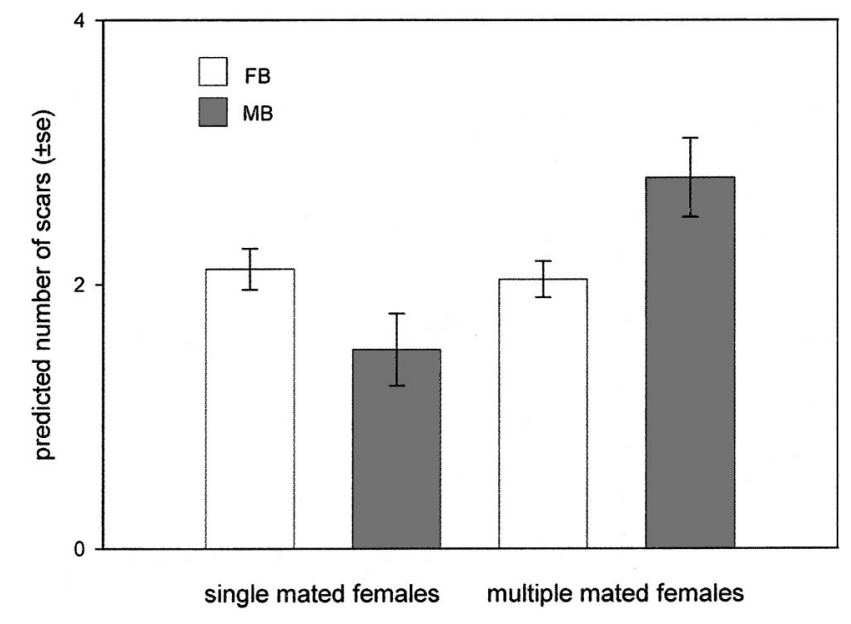

FIG. 2. Number of mating scars counted on females' bellies. Predicted mean $\pm \mathrm{SE}$ of single-mated and multiple-mated females in male-biased (MB) and female-biased (FB) populations are shown (see text for statistics).

that some mating scars were missed. The number of mating scars was not correlated with the number of sires (regression: $F_{1,127}<0.001, P=0.99$ ), showing that mating scars reflect the number of male copulation attempts (including males that repeatedly copulate with the same female) rather than multiple paternity. Polyandrous females in MB populations had more scars than both monogamous females of both treatments and polyandrous females of FB populations (treatment: $F_{1,10}$ $=3.21, P=0.10$; monogamous vs. polyandrous females: $F_{1,112}=5.83, P=0.02$; interaction: $F_{1,112}=7.66, P=0.01$; individual contrasts [Tukey-Kramer HSD]: MSR $=0.50$, polyandrous females in MB population vs. each of the other three groups: $P<0.05$ [LSM differences $\geq 1.39$ ], all other pairwise combinations $P>0.05$ [LSM differences $\leq 0.13$ ], Fig. 2).

\section{DISCUSSION}

Our study showed that in female common lizards the probability of being polyandrous does not depend on the adult population sex ratio. However, the degree of polyandry (number of multiple fathers per clutch) increased with female SVL in $\mathrm{MB}$ populations, whereas there was no increase in FB populations. This resulted in higher degrees of multiple paternity in large females from MB populations compared to large females from FB populations. Polyandrous females of MB populations also showed a greater number of mating scars than polyandrous females of FB populations, whereas no difference was observed in monogamous females. Females of MB populations produced smaller clutch sizes and polyandrous females of both treatments produced larger clutches compared to monogamous females. In males, both the proportion and the degree of polygyny were higher in FB than in $\mathrm{MB}$ populations.

\section{Relationship between Multiple-Partner Mating, Mating Scars, and Multiple Paternity}

Assessing multiple mating in males and females by genetic paternity analyses might be problematic. However, in the staged mating experiment the number of mating partners was positively correlated with the number of genetic fathers. The correlation was highly significant, showing that the number of mate partners can be predicted from the number of sires of a female's progeny or from the number of dams of a male's progeny. The correlation coefficient was not equal to one, however, indicating that some copulation attempts did not result in successful fertilizations. Thus, mechanisms such as cryptic female choice (Eberhard 1996), sperm competition, nonmature male sperm (Birkhead and Møller 1998), or copulations without sperm transfer may be involved. Consequently, our measure of multiple paternity predicts the number of mating partners only to a certain extent.

The number of mating scars was also positively correlated with multiple paternity under laboratory conditions. However, the number of mating partners was more strongly correlated with the number of mating scars, suggesting that the number of copulations predicted the number of scars better. Interestingly, no significant correlation between multiple paternity and the number of mating scars was found under field conditions. This difference is likely to stem from the experimental design. While under laboratory conditions only a limited number of males during a limited time could copulate with a given female, under field conditions more males were able to attempt to mate with a given female during a longer time. Furthermore, the same male may have had a higher probability of multiply mating with the same female compared to the laboratory situation, where females were presented to a given male for $1 \mathrm{~h}$ only. Thus, the number of mating scars predicts the number of copulation attempts only under special conditions, providing support for the idea that under field conditions the number of mating scars reflects the number of male copulation attempts, including males that repeatedly copulate with the same female, rather than multiple paternity.

\section{Effects of the Population Sex Ratio on Female Polyandry}

Females of MB populations produced 1.8 times fewer eggs than females of FB populations, and male mating attempts induced lower survival in females (J.-F. Le Galliard and P. S. Fitze, unpubl. data). Both findings show that females of MB populations suffered reduced fitness. Our results are therefore consistent with a sexual conflict in which males evolved mating behaviors that are harmful to females (Smuts and Smuts 1993). Despite the present mating costs and the increased male pressure on females in MB populations, the number of mating scars on monogamous females and the frequency of polyandry were not affected by the population sex ratio. Thus, monogamous females might have been able to choose their mate partners in both treatments and they might be better at controlling male mating attempts. Because only polyandrous females of MB populations showed an increased number of mating scars, it is unlikely that postcopulatory choices led to the observed patterns.

Several hypotheses have been proposed to explain why females mate with multiple partners (Table 3; Thornhill and Alcock 1983; Arnqvist and Nilsson 2000; Wolff and Macdonald 2004). Common lizards are autonomous after birth, do not provide parental care or nuptial gifts (Heulin 1988; 
TABLE 3. Hypotheses explaining multiple-partner mating in females and males and indication whether the experimental results are consistent with the hypotheses. Predictions for the decision to mate multiply are shown in middle column; predictions for the degree of multiple partner mating (number of partners when mating multiply) are shown in right column. Italicized predictions are consistent with the findings of our experiment.

\begin{tabular}{|c|c|c|c|}
\hline & Hypotheses & Multiple-partner mating & Degree of multiple partner mating \\
\hline \multicolumn{4}{|l|}{ Females } \\
\hline \multirow[t]{5}{*}{ Indirect benefits: } & good genes & no differences & no differences \\
\hline & genetic diversity of offspring & $\begin{array}{l}\text { no differences or higher in male } \\
\text { population }\end{array}$ & $\begin{array}{l}\text { no differences or higher in male } \\
\text { population }\end{array}$ \\
\hline & ensure fertilization & no differences & no differences \\
\hline & bet hedging & no differences & no differences \\
\hline & preferred male not available & $\begin{array}{l}\text { no differences or higher in female } \\
\text { population }\end{array}$ & $\begin{array}{l}\text { no differences or higher in female } \\
\text { population }\end{array}$ \\
\hline \multicolumn{2}{|c|}{ Inherited mating tendency } & no differences & no differences \\
\hline \multicolumn{4}{|l|}{ Males } \\
\hline \multirow{2}{*}{\multicolumn{2}{|c|}{$\begin{array}{l}\text { Male-male competition } \\
\text { Female choice }\end{array}$}} & higher in female population & higher in female population \\
\hline & & no differences & $\begin{array}{l}\text { no differences or higher in female } \\
\text { population }\end{array}$ \\
\hline
\end{tabular}

Clobert et al. 1994; Léna and de Fraipont 1998), and the nutrition content of the sperm is low (Depeiges et al. 1987); therefore, it is unlikely that polyandry is explained by additional benefits obtained due to multiple-partner mating such as parental care, nuptial gifts, or sperm. Polyandrous females produced larger clutches in MB and FB populations, suggesting that other direct benefits (e.g., stimulation of the ovulation; Gromko and Newport 1984; Opp and Prokopy 1986; Arnqvist and Nilsson 2000; Sheldon 2000; Uller and Olsson 2005) might explain why females of this species mate with multiple males. However, polyandry was not directly manipulated in our study, and thus the differences in clutch size may be due to intrinsic differences between monogamous and polyandrous females (i.e., polyandrous females are of better quality) rather than due to direct benefits of multiple paternity.

Females may also gain indirect benefits from multiple paternity (e.g., for a review see Birkhead and Møller 1998). Males were distributed randomly with regard to SVL and body mass among populations at the start of the experiment and in May 2003 (SVL: $F_{1,10}=0.85, P=0.38$; body mass: $\left.F_{1,10}=0.76, P=0.40\right)$, variances in male traits were not different between treatments in 2003 (SVL: $F_{1,10}=1.29, P$ $=0.28$; body mass: $\left.F_{1,10}=0.04, P=0.84\right)$, and males were abundant in all populations (MB populations: range $=10$ 27 males, mean $=16.0 \pm 2.5 \mathrm{SE}$ males; FB populations: range $=16-37$, mean $=23.2 \pm 2.9 \mathrm{SE}$ males; $F_{1,10}=5.41$, $P=0.04)$; therefore, females of both treatments would have been able to choose from males of similar quality and may also have copulated with several different males. Thus, no differences in the proportion of polyandrous females would have been predicted for most of the indirect benefit hypotheses (Table 3).

Our study is consistent with the hypotheses that females mate with multiple partners either to acquire good genes for their offspring, increase the genetic diversity of the offspring, ensure fertilization, hedge against sterility and genetic defects of their mating partners, or because the preferred males are not available at the time of mating (Table 3, see also Olsson and Madsen 1996). However, our results do not support the hypothesis that females produce clutches fathered by multiple partners due to male sexual harassment (Table 3). Alternative to the indirect benefits hypotheses, polyandry might be a nonadaptive inherited mating tendency due to selection favoring multiple-partner mating in males (Halliday and Arnold 1987).

Our study is consistent with the hypotheses that females mate with multiple partners due to direct benefits leading to increased egg production, due to indirect benefits, or due to an inherited mating tendency. It further shows that population sex ratio cannot explain the mating tactic (monogamy vs. polyandry) of females.

\section{Effects of the Population Sex Ratio on Polyandrous Females}

In polyandrous females, the number of different mating partners (the degree of polyandry) depended on the population sex ratio and the number of mating scars was higher in $\mathrm{MB}$ than in FB populations. Multiple paternity increased with the female's body size in MB populations, but it was size independent in FB populations. These results are consistent with the hypothesis that the number of multiple partners in polyandrous females was controlled by male sexual harassment (Table 3 ). The more pronounced effects of male sexual harassment on larger females could have three different explanations. First, larger females, who produce larger clutches, might be more attractive to males (Avery 1975). Second, we manipulated the adult sex ratio and thus our manipulation might have disproportionately affected the adult and large females due to size-assortative mating (Olsson 1993). Finally, the costs of mating (e.g., through mechanical damage leading to infection, sexually transmitted disease) may escalate as a function of mate number (Birkhead and Møller 1998). Large females could tolerate a larger number of mates if the costs of mating would be ameliorated as a function of female size.

To summarize, our study shows that polyandrous females in $\mathrm{MB}$ populations had more interactions with males and that the degree of polyandry was controlled by male sexual harassment. However, whether males forced females to copulate 
against their will, females mated with more males to reduce the cost from resisting the males' mating attempts (Arnqvist 1992; Smuts and Smuts 1993), or polyandrous females simply accept any encountered males cannot be unraveled by this experiment.

\section{Effects of the Population Sex Ratio on Male Polygyny}

Mating with multiple females is commonly adaptive in males, as it directly enhances reproductive success (Shuster and Wade 2003). Consequently, polygyny could be limited by scramble competition or by direct male-male competition, which should increase in MB compared to FB populations (Kvarnemo and Ahnesjo 1996; Table 3). However, polygyny could also be determined by female choice only. Because we found that the proportion of polyandrous females was not affected by the population sex ratio, the latter hypothesis would imply that a similar proportion of males should be polygynous in both treatments or that males of $\mathrm{MB}$ populations should be more polygynous because they were able to influence the female's degree of polyandry. The finding that both the proportion and the degree of polygyny were increased in FB populations indicates that female choice does not determine polygyny and that polygyny is controlled by scramble competition or direct male-male competition. The lack of a significant sex-ratio treatment on polygyny when controlling for the number of fertilizable eggs per population shows that the competition for mate partners is proportional to the number of available eggs. This result is consistent with Arnqvist's (1992) study on multiple-partner mating in male water striders.

In summary, our study suggests that polyandry is hierarchically controlled by both sexes and that polygyny is controlled by mating competition among males for receptive females. While the proportion of polyandrous females was independent of the population sex ratio, and thus likely to be controlled by females, the degree of polyandry was most likely proximally controlled by males through sexual harassment. Polyandrous females produced larger clutches in all treatments, suggesting that multiple paternity might be advantageous. Because females of MB populations produced smaller clutches, our study further indicates that male sexual harassment is costly for females of MB populations and thus that the sexual conflict over multiple-partner mating is increased in MB populations. Our results reinforce the view that sexual harassment by males might be common in vertebrates with no pair bond and no mate guarding and thus might influence female mating tactics in these species (Wolff and Macdonald 2004).

\section{ACKNOWLEDGMENTS}

We thank J. Cote, D. Mersch, and M.-L. Jarzat for field assistance and N. B. Davies, K. Isvaran, S. Quader, C. Spottiswoode, and two anonymous reviewers for discussion and comments on the manuscript. The work was supported by the French Ministry of Education and Research, the European Research Training Network 'ModLife' (HPRN-CT-200000051), the Federal Office of Education and Science (BBW no. 01.0254 to P.S.F), and the Swiss National Science Foundation (no. PBBEA-104428 to P.S.F).

\section{Literature Cited}

Andersson, M. 1994. Sexual selection. Princeton Univ. Press, Princeton, NJ.

Arnqvist, G. 1992. The effects of operational sex-ratio on the relative mating success of extreme male phenotypes in the water strider Gerris odontogaster (Zett) (Heteroptera, Gerridae). Anim. Behav. 43:681-683.

- 2004. Sexual conflict and sexual selection: lost in the chase. Evolution 58:1383-1388.

Arnqvist, G., and T. Nilsson. 2000. The evolution of polyandry: multiple mating and female fitness in insects. Anim. Behav. 60: 145-164.

Avery, R. A. 1975. Clutch size and reproductive effort in the lizard Lacerta vivipara Jacquin. Oecologia 19:165-170.

Bateman, A. J. 1948. Intra-sexual selection in Drosophila. Heredity $2: 349-368$.

Bauwens, D., and R. F. Verheyen. 1985. The timing of reproduction in the lizard Lacerta vivipara: differences between individual females. J. Herpetol. 19:353-364.

Birkhead, T., and A. P. Møller. 1998. Sperm competition and sexual selection. Academic Press, San Diego, CA.

Boudjemadi, K. 1999. Influence de la connexion entre populations sur leur viabilité: une approche expérimentale de la fragmentation des habitats. Laboratoire d'écologie, Pierre et Marie Curie, Paris VI, Paris.

Boudjemadi, K., J. Lecomte, and J. Clobert. 1999a. Influence of connectivity on demography and dispersal in two contrasting habitats: an experimental approach. J. Anim. Ecol. 68: 1207-1224.

Boudjemadi, K., O. Martin, J. C. Simon, and A. Estoup. 1999b. Development and cross-species comparison of microsatellite markers in two lizard species, Lacerta vivipara and Podarcis muralis. Mol. Ecol. 8:518-520.

Byrne, P. G., and J. D. Roberts. 1999. Simultaneous mating with multiple males reduces fertilization success in the myobatrachid frog Crinia georgiana. Proc. R. Soc. Lond. B. 266:717-721.

_ 2000. Does multiple paternity improve fitness of the frog Crinia georgiana? Evolution 54:968-973.

Choe, J. C., and B. J. Crespi. 1997. Mating systems in insects and arachnids. Cambridge Univ. Press, Cambridge, U.K.

Clobert, J., M. Massot, J. Lecomte, G. Sorci, M. De Fraipont, and R. Barbault. 1994. Determinants of dispersal behavior: the common lizard as a case study. Pp. 183-206 in L. J. Vitt and E. R. Pianka, eds. Lizard ecology: historical and experimental perspectives. Princeton Univ.Press, Princeton, NJ.

Clutton-Brock, T. H., and G. A. Parker. 1995. Sexual coercion in animal societies. Anim. Behav. 49:1345-1365.

Depeiges, A., A. Force, and J. P. Dufaure. 1987. Production and glycosylation of sperm constitutive proteins in the lizard Lacerta vivipara: evolution during the reproductive period. Comp. Biochem. Physiol. B 86:233-240.

Eberhard, W. G. 1996. Female control: sexual selection by cryptic female choice. Princeton Univ. Press, Princeton, NJ.

Gromko, M. H., and M. E. A. Newport. 1984. Sperm dependence of female receptivity to remating in Drosophila melanogaster. Evolution 38:1273-1282.

Halliday, T., and S. J. Arnold. 1987. Multiple mating by females: a perspective from quantitative genetics. Anim. Behav. 35: 939-941.

Heulin, B. 1988. Observations sur l'organisation de la reproduction et sur les comportements sexuels et agonistiques chez Lacerta vivipara. Vie Milieu 38:177-187.

Heulin, B., L. K. Osenegg, and D. Michel. 1997. Demography of a bimodal reproductive species of lizard (Lacerta vivipara): survival and density characteristics of oviparous populations. Herpetologica 53:432-444.

Kvarnemo, C., and I. Ahnesjo. 1996. The dynamics of operational sex ratios and competition for mates. Trends Ecol. Evol. 11: 404-408.

Laloi, D., M. Richard, J. Lecomte, M. Massot, and J. Clobert. 2004. Multiple paternity in clutches of common lizard Lacerta vivipara: data from microsatellite markers. Mol. Ecol. 13:719-723. 
Lecomte, J., J. Clobert, M. Massot, and R. Barbault. 1994. Spatial and behavioural consequences of a density manipulation in the common lizard. Ecoscience 1:300-310.

Lee, P. L. M., and G. C. Hays. 2004. Polyandry in a marine turtle: females make the best of a bad job. Proc. Natl. Acad. Sci. USA 101:6530-6535.

Le Galliard, J.-F., M. Le Bris, and J. Clobert. 2003. Timing of locomotor impairment and shift in thermal preferences during gravidity in a viviparous lizard. Funct. Ecol. 17:877-885.

Le Galliard, J.-F., P. S. Fitze, J. Cote, M. Massot, and J. Clobert. 2005. Female common lizards (Lacerta vivipara) do not adjust their sex-biased investment in relation to the adult population sex ratio. J. Evol. Biol. 18:1455-1463.

Léna, J. P., and M. de Fraipont. 1998. Kin recognition in the common lizard. Behav. Ecol. Sociobiol. 42:341-347.

Littell, R. C., G. A. Millinken, W. W. Stroup, and R. D. Wolfinger. 1996. SAS systems for mixed models. SAS Institute, Inc., Cary, NC.

Madsen, T., and R. Shine. 1992. Determinants of reproductive success in female adders, Vipera berus. Oecologia 92:40-47.

Marshall, T. C., J. Slate, L. E. B. Kruuk, and J. M. Pemberton. 1998. Statistical confidence for likelihood-based paternity inference in natural populations. Mol. Ecol. 7:639-655.

Martin, O. Y., and D. J. Hosken. 2003. The evolution of reproductive isolation through sexual conflict. Nature 423:979-982.

Massot, M., J. Clobert, T. Pilorge, J. Lecomte, and R. Barbault. 1992. Density dependence in the common lizard: demographic consequences of a density manipulation. Ecology 73:1742-1756.

Olsson, M. 1993. Male preference for large females and assortative mating for body size in the sand lizard (Lacerta agilis). Behav. Ecol. Sociobiol. 32:337-341.

Olsson, M., and T. Madsen. 1996. Costs of mating with infertile males selects for late emergence in female sand lizards (Lacerta agilis L). Copeia 2:462-464.

Opp, S. B., and R. J. Prokopy. 1986. Variation in laboratory ovi- position by Rhagoletis pomonella (Diptera: Tephritidae) in relation to mating status. Ann. Entomol. Soc. Am. 79:705-710.

Parker, G. A. 1983. Mate quality and mating decisions. Pp. 141166 in P. Bateson, ed. Mate choice. Cambridge Univ.Press, Cambridge, UK.

Pizzari, T., and R. R. Snook. 2003. Perspective: Sexual conflict and sexual selection: chasing away paradigm shifts. Evolution 57: 1223-1236.

Quinn, G. P., and M. J. Keough. 2002. Experimental design and data analysis for biologists. Cambridge Univ. Press, Cambridge, U.K.

Rice, W. R. 1996. Sexually antagonistic male adaptation triggered by experimental arrest of female evolution. Nature 381:232-234.

Sheldon, B. C. 1993. Sexually transmitted disease in birds: occurrence and evolutionary significance. Philos. Trans. R. Soc. B 339:491-497.

. 2000. Differential allocation: tests, mechanisms and implications. Trends Ecol. Evol. 15:397-402.

Shuster, S. M., and J. M. Wade. 2003. Mating systems and strategies. Princeton Univ. Press, Princeton, NJ.

Smuts, B. B., and R. W. Smuts. 1993. Male aggression and sexual coercion of female in nonhuman primates and other mammals: evidence and theoretical implications. Adv. Stud. Behav. 22: $1-63$.

Thornhill, R., and J. Alcock. 1983. The evolution of insect mating systems. Harvard Univ. Press, Cambridge, MA.

Uller, T., and M. Olsson. 2005. Multiple copulations in natural populations of lizards: evidence for the fertility assurance hypothesis. Behaviour 142:45-56.

Wigby, S., and T. Chapman. 2004. Female resistance to male harm evolves in response to manipulation of sexual conflict. Evolution 58:1028-1037.

Wolff, J. O., and D. W. Macdonald. 2004. Promiscuous females protect their offspring. Trends Ecol. Evol. 19:127-134.

Corresponding Editor: K. Schwenk 